\title{
Mobilização e predação: a guerra contra espécies invasoras sob duas perspectivas
}

Mobilization and predation: the war against invasive species from two perspectives

\author{
Caetano Sordi* \\ *Instituto do Patrimônio Histórico e Artístico Nacional - Porto Alegre, RS, Brasil \\ caetano.sordi@gmail.com \\ https://orcid.org/0000-0003-2334-8096
}




\title{
Resumo
}

As lógicas de biossegurança contemporâneas se baseiam em um modelo de pensamento derivado da estratégia militar. Não obstante, que concepções sobre a natureza mesma da guerra perpassam as reações sociais à presença de ameaças biológicas, como espécies exóticas invasoras? A partir da etnografia do manejo de javalis asselvajados no sul do Brasil, argumento neste artigo que tanto os discursos sobre invasões biológicas quanto suas críticas se inspiram em um paradigma estratégico e exclusional do conflito militar, baseado, por sua vez, em um imaginário territorial das relações ecológicas. Alternativamente, em linha com a antropologia simétrica e algumas reflexões de Lévi-Strauss sobre o canibalismo, sugiro que outros modelos do que seja uma guerra podem ser mobilizados para se pensar o conflito entre sociedade e riscos biológicos, mais próximos da lógica de predação familiarizante que caracteriza a relação agonística com a alteridade perigosa nas cosmologias ameríndias.

Palavras-chave: biossegurança; espécies exóticas invasoras; guerra; javali.

\begin{abstract}
Contemporary biosecurity relies on a military mode of thinking. Notwithstanding, what ideas about the nature of war itself permeate social reactions to biological threats, such as invasive alien species? Drawing on an ethnography of wild boar management in Southern Brazil, I argue in this article that both the discourse on biological species and its criticism are inspired by a strategic, exclusional, paradigm of military conflict, which is in turn based on a territorial imagery of ecological relations. Alternatively, in line with symmetric anthropology and several Levi-Strauss' meditations on cannibalism, I suggest that other models of what a war is can be mobilized to think about the conflict between society and biological risks, closer to the logic of predation that characterizes the agonistic relation with the dangerous Other in Amerindian cosmologies.
\end{abstract}

Keywords: biosecurity; alien invasive species; war; wild boar. 


\section{Introdução}

Em 2011, a Associação Gaúcha de Controle do Javali Asselvajado (Agaja), entidade sediada na cidade de Caxias do Sul (RS), enviou uma longa carta ao general de brigada então responsável pela Divisão de Fiscalização de Produtos Controlados (DFPC) do Exército Brasileiro. ${ }^{1}$ No documento, o presidente da associação descrevia os indivíduos da espécie Sus scrofa nos seguintes termos, bastante expressivos:

Estes animais têm presas longas e intercruzadas, o que mantém arestas afiadas e pontiagudas, tornando-as verdadeiras lâminas que o javali habitualmente usa para perfurar e dilacerar carne e ossos de oponentes em seus ataques. Além dessas presas, o javali é dotado de musculatura robusta, o que lhe confere expressiva resistência e força, bem como de uma couraça natural (sequência de camadas consolidadas e compactas de couro, cartilagem e gordura com espessura superior a 5 centímetros em machos adultos) que envolve a região anterior do tronco, recobrindo a coluna vertebral, pescoço e costelas até a região lateral do peito.

Verdadeiras máquinas de guerra, "capazes de percorrer distâncias de até cem metros mesmo alvejados por tiros de fuzil", os javalis seriam animais cujo controle demandaria o acesso de seus "combatentes" a equipamento bélico capaz de fazer frente a tamanha ameaça. Estes, por sua vez, seriam "homens do campo, criadores, pequenos e grandes agricultores, seus parentes e amigos que moram nas cidades", ciosos dos danos causados pelos suínos asselvajados ao meio ambiente e à produção rural. Conforme a solicitação do presidente, a "guerra" em curso contra o javali requereria revólveres com calibres mais potentes que aqueles ora liberados para caçadores no Brasil, tais como o .357, o .44, o .454, o .460 e o .500. O apelo específico pela liberação de armas curtas com maior poder de fogo derivaria do fato de a maior parte dos combates com o animal se dar por meio de "caça assessorada por matilhas de cães treinados",

1 A DFPC é um órgão ligado ao Comando Logístico do Exército Brasileiro. Responsabiliza-se pela autorização e fiscalização da produção e comercialização de material bélico em território nacional. Cabe a ela a concessão de registro de tipo CAC (caçador, atirador e colecionador) por pessoas físicas. 
em zonas de mata "com capoeira alta e densa, típica das paisagens gaúchas e preferidas pelo javali". Nessas condições,

a aproximação segura do caçador nem sempre é possível. Ao notar que o caçador se aproxima, um javali, mesmo imobilizado, pode reunir forças ou imprimir movimentos distintos, o que pode ocasionar um rápido escape, atacando tudo que estiver na rota de fuga que ele selecionar. [...] Nestas situações, o uso de uma arma curta, que seja mais fácil de manusear, sem os problemas de movimentação de uma arma longa em áreas vegetadas, que possa fazer disparos com energia suficiente para parar a carga de um animal em fuga ou no embate, é de fundamental importância.

Até então autorizada somente no Rio Grande do Sul, e em caráter provisório, a captura e abate legal de javalis e suas cruzas com porcos domésticos para fins de controle ecológico viria se tornar política pública permanente e nacional apenas em janeiro de 2013, quando da decretação da sua nocividade por parte do Instituto Brasileiro do Meio Ambiente e dos Recursos Naturais Renováveis (2013), o Ibama. Posteriormente, uma instrução técnico-normativa do Exército (Brasil, 2014), datada de 30 abril de 2014, normatizaria o equipamento a ser utilizado no abate de suínos de vida livre, não admitindo calibres inferiores a $6 \mathrm{~mm}$ (.240) para armas longas, como fuzis e espingardas, e 8,9 mm (.357) para armas curtas, como revólveres e pistolas.

Todavia, como venho discutindo em trabalhos recentes (Sordi, 2015, 2017, 2018; Sordi; Lewgoy, 2017), ${ }^{2}$ o acolhimento sistemático das demandas antijavali por parte do Estado desde meados da década de 1990 não parece ter sido suficiente para pacificar as controvérsias em torno da espécie existentes no Brasil. Ao contrário, constituídos como animais da discórdia (Manceron; Roué, 2009) em diversas partes do mundo, ${ }^{3}$ os javalis e sua presença parecem servir

2 Este artigo é fruto do projeto de pesquisa "Antropologia e espécies animais exóticas: o caso do javali europeu asselvajado no Brasil” (CNPq - Edital Universal 14/2014-2017), coordenado por Bernardo Lewgoy.

3 O Sus scrofa está listado entre as "100 piores espécies invasoras do mundo" pelo painel sobre invasões biológicas da União Internacional para a Conservação da Natureza (UICN) (Lowe et al., 2004). Trata-se de um animal com grande valência ecológica, o que é potencializado por sua milenar sinantropia (Barrios-García; Ballari, 2012). 
cada vez mais como caixas de ressonância de outros conflitos que perpassam a sociedade brasileira como um todo, especialmente aqueles relacionados ao advento de uma nova hegemonia conservadora no país, simbolicamente sustentada sobre o "direito de autodefesa" e o ruralismo.

Assim, durante as eleições gerais de 2018, Ricardo Salles, então candidato a deputado federal pelo Partido Novo de São Paulo, fez do controle do javali asselvajado uma das suas principais bandeiras de campanha, comparando o combate à espécie exótica com a defesa armada da propriedade privada contra o Movimento dos Trabalhadores Sem Terra (MST). O número da sua candidatura, por sua vez, evocava diretamente um dos calibres mais utilizados pelos caçadores de suínos: .30.06. Em 2019, com Salles já ocupando o posto de ministro do Meio Ambiente do governo Jair Bolsonaro (PSL), o Ibama reformulou a instrução normativa de 2013 que autorizava o controle cinegético do javali no país. Entre as demandas de caçadores e proprietários rurais incorporadas no novo documento, enumera-se a recomendação da utilização de jaulas-currais "modelo pampa", ${ }^{4}$ a criação de um Sistema Integrado de Manejo de Fauna (Simaf), bem como a liberação explícita do uso de armas brancas, cães de acosso e agarre por parte dos controladores ${ }^{5}$ (Instituto Brasileiro do Meio Ambiente e dos Recursos Naturais Renováveis, 2019). Em diversos veículos e páginas da internet ligados ao agronegócio, a mudança na legislação foi comemorada como um passo importante na "guerra contra o javali", ao passo que redes ligadas à militância por direitos animais associaram a nova normativa a outros "retrocessos" levados a cabo pelo novo governo.

A gramática agonística empregada pelos inimigos dos javalis, assim como sua recorrente articulação com outras batalhas ideológicas hoje travadas na esfera pública brasileira, parecem reforçar, sob muitos aspectos, o que diversos trabalhos têm salientado há pelo menos duas décadas. Qual seja, a percepção

4 A jaula-curral "modelo pampa" é fruto da cooperação entre os gestores da Área de Proteção Ambiental do Ibirapuitã (RS), ligados ao Instituto Chico Mendes de Preservação da Biodiversidade (ICMBio), e a "Equipe Javali no Pampa", formada por um agrônomo, um biólogo e um veterinário.

5 A instrução normativa $n^{\circ}$ 03/2013, de 31 de janeiro de 2013 (Instituto Brasileiro do Meio Ambiente e dos Recursos Naturais Renováveis, 2013) era omissa quanto ao uso de cães na captura de javalis, o que potencializou o embate entre caçadores e organizações defensoras dos direitos animais. 
de que as políticas de biossegurança contemporâneas têm se baseado, em maior ou menor medida, em uma lógica prático-discursiva derivada da estratégia militar (Fortané; Keck, 2015). No caso da chamada biologia das invasões, campo da ecologia dedicado ao estudo das chamadas espécies exóticas invasoras e seu impacto sobre os ambientes receptores, esta tem sido uma tendência particularmente forte, o que pode ser atestado pela proliferação de metáforas marciais nos discursos sobre o tema, tanto os leigos quanto os especializados (Simberloff, 2003, 2011, 2013). Não por acaso, muitos biólogos reticentes quanto à objetividade dos conceitos de "exotismo" e "invasão" têm defendido a utilização de um vocabulário mais "neutro" para tratar da matéria (Colautti; MacIsaac, 2004; Larson, 2005), ao passo que diversos autores ligados às humanidades têm alertado para as conotações xenófobas e racistas dos discursos belicosos sobre espécies invasoras (Coates, 2011; Comaroff; Comaroff, 2001; Lidström et al., 2015; Potts, 2009; Sagoff, 2011).

No que se segue, mais do que reconstituir essa controvérsia, buscarei dar um passo atrás e investigar que concepções do que seja uma "guerra" animam o discurso sobre espécies exóticas invasoras e, ato contínuo, também as suas críticas. Nesse sentido, partirei de dois pressupostos, um teórico e outro metodológico. Teoricamente, partirei da ideia de que a guerra é um fenômeno que está longe de comportar uma definição unívoca, muito embora ofereça uma série de elementos importantes para se conceber a relação com a alteridade em distintos contextos (Leirner, 2005). Metodologicamente, inspirado pela antropologia simétrica (Goldman, 2003; Latour, 1994) e por reflexões de Lévi-Strauss $(1996,2009)$ sobre os sentidos do canibalismo e da devoração como forma de relação com alteridade perigosa, ${ }^{6}$ procurarei explorar as potencialidades do pensamento ameríndio para se analisar os impasses biopolíticos da modernidade desde um ponto de vista radicalmente outro, inclusive no que tange às questões colocadas pela contemporânea antropologia da biossegurança.

$\mathrm{O}$ argumento será estruturado da seguinte forma: primeiramente, tal como defendi em outra oportunidade (Sordi, 2018), procurarei demonstrar que as noções de guerra que subjazem aos discursos sobre invasões biológicas

6 Conforme Keck (2015a, p. 102): “O canibalismo é, na realidade, um conceito cada vez mais central no pensamento de Lévi-Strauss, mas ele aparece já no final dos anos de 1950, e justifica toda a releitura do totemismo que levará à abertura do caminho das Mitológicas nos anos de 1970." 
derivam de um imaginário ambiental moderno muito específico, que classificarei como vestfaliano e clausewitziano. Vestfaliano, porque, à imagem do sistema internacional erigido em finais do século XVII, coloca a questão da soberania nacional e do respeito às fronteiras territoriais em primeiro plano; clausewitziano, porque, como na obra do clássico polemologista prussiano Carl von Clausewitz (1780-1831), considerado "o pai da guerra moderna", situa a resposta violenta à ameaça externa a partir de um esforço de mobilização entre população e aparelho estatal.

Em seguida, explorarei a etnografia que realizei junto ao manejo do javali na fronteira brasileiro-uruguaia para sugerir que, em paralelo a esse paradigma moderno do conflito bélico, outros modelos do que seja uma guerra podem ser mobilizados para se pensar conflito entre sociedade e ameaças biológicas desde um ponto de vista antropológico, mais próximos da lógica de predação familiarizante que caracteriza a relação agonística com a alteridade nas cosmologias ameríndias (Fausto, 2001, 2002; Viveiros de Castro, 2011, 2015). Assim, se em um modelo mais convencional de guerra, salienta-se a aplicação de um pensamento estatal, territorial e exclusional, para se conceber o conflito com outras espécies, em outro, derivado do contraste com o paradigma inclusional presente no pensamento ameríndio, destaca-se a incorporação do inimigo e sua potência como forma de garantir a vitalidade do grupo.

Evidentemente, ao propor tal aproximação, não busco defender que haja quaisquer continuidades cosmológicas fortes entre meus interlocutores e os povos indígenas nas terras baixas sul-americanas. Ao contrário, busco recorrer a outro conjunto de coordenadas ontológicas, diferentes daquelas que constituem o imaginário moderno e ocidental sobre a guerra, para, através da comparação e do contraste, trazer à tona aspectos da relação com a ameaça não humana por vezes obscurecidos nas análises mais frequentes. Da mesma forma, entendo que a justaposição com o pensamento indígena, levado a sério como metafísica alternativa (Viveiros de Castro, 2015), nos permite superar certas armadilhas evolucionistas contidas na categoria de "guerra pré-moderna", no que me filio a Leirner (2005) quando este apresenta a guerra ameríndia como um paradigma substantivo para se pensar antropologicamente o conflito bélico em geral. Por fim, o que proponho neste artigo não está muito distante do que Goldman (2003, p. 460) apresenta como o objetivo de uma teoria etnográfica, isto é, "elaborar um modelo de compreensão de um objeto social 
qualquer (linguagem, magia, política) que, mesmo produzido em e para um contexto particular, seja capaz de funcionar como matriz de inteligibilidade em outros contextos". Em outras palavras: de que maneira a guerra ameríndia pode auxiliar-nos a compreender a "guerra ao javali" e outras batalhas biossecuritárias para além das concepções mais convencionais da guerra ocidental?

\section{O imaginário ecológico vestfaliano e a guerra clausewitziana contra espécies invasoras}

Ainda que a preocupação com o impacto de organismos exóticos sobre ambientes nativos possua antecedentes notórios na biologia, como John Henslow (1796-1861), Hewett Watson (1804-1881) e o próprio Charles Darwin (1809-1882), considera-se que a moderna biologia das invasões tenha sido fundada pelo ecólogo e zoólogo britânico Charles Sutherland Elton (1900-1991), com a publicação de seu clássico The ecology of invasions by animals and plants (1958). Nesse livro, fruto de duas conferências de rádio proferidas pelo autor para a $\mathrm{BBC}$, a contenção de organismos invasores é qualificada como "uma das batalhas decisivas da história" (Elton, 1958 apud Pearce, 2015, p. 140, tradução minha), uma vez que, no conflagrado mundo de então, não seriam apenas "bombas nucleares e guerras que nos ameaçariam", mas também "explosões biológicas" (Elton, 1958 apud Pearce, 2015, p. 140, tradução minha). Para Smout (2011, p. 60, tradução minha), em um contexto de crescentes preocupações relacionadas à segurança nacional derivadas do Pós-Guerra e do advento da Guerra Fria, Elton acreditava que a melhor defesa contra organismos exóticos deletérios seria um "robusto ecossistema nativo repleto de espécies autóctones", preservado em seu equilíbrio coevolutivo.

Após algumas décadas de latência junto à comunidade científica, a preocupação com invasões biológicas ganhou tração a partir dos anos 1970-1980, com a consolidação da biodiversidade como principal valor do discurso ambiental internacional. Nesse contexto, firmou-se a identificação das espécies exóticas invasoras como a segunda maior ameaça aos ecossistemas nativos, perdendo apenas para a ação direta do ser humano sobre os ambientes naturais. A Convenção da Diversidade Biológica (CDB), publicada na Convenção das Nações Unidas para o Meio Ambiente de 1992 (cf. Brasil, 2000), obriga os países 
signatários a "impedir que se introduzam" e a "controlar ou erradicar espécies exóticas que ameacem os ecossistemas, habitats ou espécies" (Brasil, 2006, p. 5). Além disso, Jeffrey McNeely (2011) identifica a existência de mais de 40 convenções, acordos e protocolos sobre o tema internacionalmente, o que, segundo esse autor, evidencia uma tensão quase insolúvel entre a necessidade de conter invasões biológicas, de um lado, e a ideologia global da conectividade e do livre comércio, de outro.

Com efeito, é difícil dissociar o problema da invasão biológica de seu componente geopolítico e econômico, na medida em que, como recorda Crosby (2011), foi a expansão marítima do Ocidente entre os séculos XV e XIX que começou a "suturar as cicatrizes de Pangeia", aproximando ecologias muito distintas umas das outras e segregadas por milênios de dispersão evolutiva. Nesse sentido, em analogia com o "pessimismo sentimental" (Sahlins, 1997) de muitos antropólogos quanto ao desaparecimento da diversidade cultural, os biólogos das invasões contemporâneos estão particularmente preocupados com o efeito das espécies introduzidas sobre comunidades ricas em espécies endêmicas, assim como com a consolidação do que têm chamado de "Homogeoceno" (Simberloff, 2013), isto é, a homogeneização da fauna e da flora globais causada pela ação do Homo sapiens.

Outros autores, entretanto, tecem críticas à biologia das invasões, seu discurso e seus pressupostos. Para o ecólogo Daniel Simberloff (2013), , essas críticas podem ser classificadas em dois tipos: oposição científica, na qual os autores questionam a validade analítica de conceitos como "exótico", "invasor", "nativo" e "dano", e acusações de xenofobia, nas quais se denuncia o caráter bélico das metáforas empregadas. Em defesa da subdisciplina, Simberloff (2013) pondera que as analogias militares empregadas no campo são, ao fim e ao cabo, as mesmas utilizadas nas políticas de saúde pública para declarar "guerra" a doenças infecciosas e seus vetores - como bem demonstram, aliás, as reações oficiais ao Aedes aegypti no Brasil (Segata, 2016). Da mesma forma, relembra que já Darwin e Wallace, nos primórdios da biologia evolutiva, falavam em plantas e animais

7 Daniel Simberloff (1942-) é um ecólogo e biólogo evolucionário norte-americano, professor na Universidade do Tennessee. Estudou e colaborou com Edward O. Wilson (1929-) no desenvolvimento de sua teoria sobre biogeografia insular. É considerado uma das principais autoridades contemporâneas no campo da biologia das invasões, sendo também editor-em-chefe do prestigioso periódico Biological Invasions. 
invasores, em uma época na qual "os jornais eram cheios de mapas ilustrando a movimentação de tropas" (Simberloff, 2013, p. 249, tradução minha). Por fim, Simberloff alega que, paralelamente à "similaridade cartográfica" entre ameaças militares e biológicas, seria de fato estranho "se a imprensa e os agentes públicos não fizessem uso de metáforas militares para os mais diversos tipos de mobilizações", como "guerra à pobreza", "luta contra o câncer", "batalha pelas mentes das crianças contra as drogas", entre outros exemplos (Simberloff, 2013, p. 249, tradução minha).

Por outro lado, o geógrafo Chris Warren (2011, p. 70) argumenta que embora o discurso sobre espécies exóticas não seja inerentemente xenófobo, haveria um grande risco de ser interpretado dessa maneira, uma vez que a terminologia adotada pela biologia das invasões teria criado uma "linguagem híbrida", que misturaria "julgamentos de valor com conceitos científicos". Fred Pearce (2015, p. 140, tradução minha), por fim, defende que "ainda que seja insensato acusar os ambientalistas contemporâneos de serem fascistas ocultos", o legado político dos discursos inflamados contra espécies exóticas seria, no mínimo, inquietante. ${ }^{8}$ Basta recordar, como faz o próprio Simberloff (2003, p. 181), da cruzada levada a cabo pelo Escritório de Mapeamento Vegetal do III Reich para "limpar a paisagem alemã de substâncias desarmônicas", ou, no outro extremo do espectro político, das mobilizações contra ratos, moscas, mosquitos e pássaros conclamadas por Mao Zedong como parte do "Grande Salto Adiante" na China comunista (Dikötter, 2011).

Controvérsias terminológicas à parte, não deixa de chamar atenção o fato de que, em um cenário constituído por fluxos e linhas de mobilidade consideradas de risco por parte do Estado, como as migrações, o terrorismo, o tráfico internacional de drogas, armas, pessoas e animais silvestres, fluxos e mobilidades de outra natureza - justamente, provenientes do domínio ontológico que o discurso moderno classificará como a natureza (Latour, 1994) - evoquem consternações análogas em leigos e especialistas. Tudo se passa como se elementos externos a um determinado "regime de domesticidade" (Sordi, 2017) tivessem a

8 Fred Pearce (1951-) é um jornalista e divulgador ambiental britânico. Em seu livro The new wild: why invasive species will be nature's salvation (Pearce, 2015), remonta o desenvolvimento histórico da biologia das invasões e discute seus pressupostos, argumentando em favor de uma visão mais favorável ao papel das espécies exóticas no funcionamento dos ecossistemas. 
capacidade de perturbar o equilíbrio interno a esse mesmo regime, seja ele um Estado nacional, um ambiente natural ou uma paisagem cultural, e, por conta disso, devessem ser contidos, controlados, erradicados ou excluídos por aqueles que nele exercem algum tipo de soberania ou ordenamento.

Mas quais seriam as origens desse modo específico de conceber tanto a ordem natural quanto a ordem civil ou social? Para responder a essa questão, creio ser útil retornarmos à ideia de uma "similaridade cartográfica" entre os dois tipos de ameaça, bélica (humana) e biológica (não humana), de que fala Simberloff (2013). Assim, se, como afirmou Lacoste (1989) em seu célebre ensaio sobre os usos políticos da geografia, ela serve, antes de tudo, para fazer a guerra, talvez seja desdobrando os sentidos inerentes a essa similaridade cartográfica que encontraremos os pressupostos que animam as concepções de "guerra" que aqui nos interessam.

De fato, em um ensaio denominado "Globes and spheres", Ingold (2000) lança a tese de que o imaginário ambiental moderno está calcado em uma "mirada global" (global outlook) sobre a superfície da Terra, afim à geopolítica militar do Estado e do colonialismo. ${ }^{9}$ Segundo esse autor, tal como na cartografia de estado-maior, voltada para a guerra, a representação moderna sobre os ambientes naturais tenderia a ver a superfície terrestre como um tabuleiro, seccionado em áreas discretas, bem definidas e delimitadas, sobre as quais ocorre um jogo de ocupação e conquista. Como em um atlas, esses domínios podem ser tanto de ordem política, como países, estados e regiões, quanto física, como biomas, ecossistemas, províncias minerais, climáticas e hidrográficas. Nos termos de Ingold (2000, p. 214, tradução minha), a Terra, concebida como uma colcha de retalhos, seria assim fragmentada em "superfícies previamente dadas, esperando para serem ocupadas, para serem colonizadas, primeiramente por outros seres vivos e, logo em seguida, pela civilização humana".

Entendo que esta forma de conceber o planeta remete a uma topologia verdadeiramente vestfaliana, que perpassaria tanto o imaginário político, quanto ecológico da modernidade. Em geopolítica e relações internacionais, o termo "vestfaliano" refere-se ao paradigma oriundo da Paz de Vestfália, isto é, da série de tratados estabelecidos no século XVII que deram fim à Guerra dos Trinta

9 Não por acaso, Helmreich (2005) nota que a chegada dos europeus ao Havaí é empregada como marco temporal pelos biólogos daquele arquipélago para definir espécies "exóticas" e espécies "nativas". 
Anos (1618-1648) e aos enfrentamentos entre católicos e protestantes na Europa do Norte e Central. Tal como concebido à época e, de certa forma, vigente até hoje, o sistema vestfaliano erigiu os Estados nacionais como os principais agentes das relações internacionais, impondo a questão da soberania e do respeito às fronteiras territoriais em primeiro plano. Logo, em uma topologia vestfaliana do planeta, cada unidade territorial corresponderia a um sistema fechado, ordenado, no qual, através de uma determinada economia doméstica, um poder soberano procuraria defender seu domínio contra as ameaças externas. Não por acaso, em outro ensaio a respeito do tema, Ingold (2015, p. 155, tradução minha) recorda a origem comum entre "ecologia" e "economia" na ideia de domesticidade como arranjo harmônico:

Ambos os termos partilham uma raiz comum, a palavra grega para "casa" (oikos). Economia é gestão doméstica [house-holding]. Na definição de ecologia - um termo cunhado pelo zoologista Ernst Haeckel em 1866 -, a própria natureza torna-se um domínio doméstico [household] no qual todo e cada organismo faz a sua parte.

De fato, a ideia de um balanço interno da natureza é uma metáfora fundacional da moderna ecologia, cuja história se confunde com a percepção de que o ser humano desencadeia distúrbios na natureza que perturbam seu equilíbrio original (Pearce, 2015). Há reminiscências escatológicas importantes nessa concepção da relação homem/natureza, uma vez que, como relembram os teólogos da tradição judaico-cristã, o pecado original não teria conduzido apenas a humanidade, mas a criação inteira a um estado de desgraça. Para Pearce (2015), o conceito de "clímax", formulado por Frederic Clements (1874-1945) como o último estágio alcançado pelas comunidades bióticas no processo de sucessão ecológica (Clements, 1936), estaria na base da ortodoxia do equilíbrio interno imanente à biologia das invasões, assim como de seu infinito estoque de metáforas bélicas para se referir a espécies exóticas.

Mas de que maneira esse imaginário ecológico vestfaliano se associaria a uma ideia específica do que seja uma guerra contra outras espécies? Em sua revisão do conceito em antropologia, Leirner (2005) nota que o imaginário disciplinar sobre o fenômeno bélico, ao menos no ambiente anglo-saxônico, tem sido historicamente dominado pela identificação entre guerra e Estado, ou seja, entre conflito violento e a existência de instituições especializadas, separadas 
da sociedade, responsáveis pelo exercício legítimo da violência, seja ela ofensiva ou defensiva, contra a ameaça externa. Por outro lado, a discussão francófona, calcada no "reciprocismo" do paradigma estruturalista, tenderia a encarar a guerra em termos de possibilidades formais, seja como o avesso da troca social, tal como aparece em Lévi-Strauss (2011), seja como sua anterioridade lógica, tal como na discussão travada com esse autor por Pierre Clastres (2004).

De certo modo, entendo que as metáforas bélicas que permeiam o discurso sobre espécies invasoras pertencem ao primeiro tipo de imaginário sobre a guerra, na medida em que se orientam por uma lógica de mobilização estratégica contra um inimigo externo. Como bem reconhece Simberloff (2013) nas passagens anteriormente citadas, a retórica de mobilização é útil para galvanizar a sociedade em torno de um inimigo comum, assim como para conferir suporte moral e material à instituição responsável pelo enfrentamento direto da ameaça. Esta instituição pode ser tanto o exército (literal) que combate a máquina de guerra estrangeira quanto o exército (metafórico) de especialistas, como cientistas e agentes de saúde, que combatem a proliferação de um mosquito exótico, por exemplo.

A guerra como mobilização estratégica, defesa e conquista territorial remete ao legado de Carl von Clausewitz (1780-1831), militar prussiano a quem se atribui o título de "pai da guerra moderna". Atento espectador das Guerras Napoleônicas, Clausewitz deixou uma obra póstuma e incompleta, denominada Da guerra (1832), em que desenvolve uma verdadeira filosofia do conflito bélico, compreendido em continuidade com a política, donde a célebre máxima de que "a guerra é continuação da política por outros meios”. Na obra, Clausewitz também analisa o sucesso da investida bélica como produto da sinergia entre Estado, exército e população. Ora, as guerras do século XIX observadas, analisadas e, posteriormente, influenciadas por Clausewitz são as mesmas que, segundo Simberloff (2013, p. 249), enchiam os jornais lidos por Darwin, Wallace e outros precursores da ecologia moderna com "mapas ilustrando a movimentação de tropas".

Outro aspecto importante do paradigma clausewitziano, diretamente relacionado à sua concepção de guerra como continuidade da política por outros meios, é a ideia de que a organização das forças armadas espelha o funcionamento da guerra em tempo de paz, permanecendo em estado latente de mobilização (Leirner, 2005). Nesse sentido, Fortané e Keck (2015) parecem estar corretos ao afirmarem que as contemporâneas políticas de biossegurança se 
inspiram em um modelo militar de funcionamento. $\mathrm{E}$ com efeito, para esses e outros autores (Braun, 2013; Collier; Lakoff; Rabinow, 2004), a palavra de ordem das novas lógicas biossecuritárias é preparedness, ou seja, prontidão e mobilização permanente tendo em vista a contenção do avanço externo, ou da propagação interna, de ameaças biológicas disruptivas. No entanto, seria o imaginário vestfaliano e clausewitziano de contenção territorial e mobilização estratégica o único modelo "bom para pensar" o conflito entre sociedade humana e espécies invasoras? Contemplaria ele todas as dimensões envolvidas em uma "guerra" como aquela travada entre meus interlocutores e os javalis?

\section{Vingança e incorporação da ameaça na "guerra ao javali"}

"Homem versus javali" (Zero Hora, Porto Alegre, 28/09/2014). "Produtores, técnicos e autoridades declaram guerra contra o javali" (A Plateia, Santana do Livramento, 13/12/2013). "Guerra total aos javalis na Fronteira Oeste" (Jornal do Comércio, Porto Alegre, 19/08/2013). Não há dúvidas de que manchetes como essas, assim como os exemplos trazidos na introdução, atestam a vigência de uma gramática bélica para se referir aos suínos asselvajados no Rio Grande do Sul, especialmente na zona contígua à conurbação internacional Santana do Livramento (Brasil)-Rivera (Uruguai). Foi nessa região, culturalmente identificada com a pecuária extensiva, e na qual os javalis são odiados, primariamente, por seus ataques à ovinocultura, onde conduzi minha etnografia, entre maio de 2014 e maio de 2016.

Sob muitos aspectos, tratava-se de um local privilegiado para realizar uma etnografia das reações sociais à presença dos javalis no Brasil. Primeiramente, devido ao avançado estado da dispersão da espécie no bioma Pampa, tanto no Brasil quanto no Uruguai e Argentina. ${ }^{10}$ Em segundo lugar, pelo destaque que a

10 Casos de feralização do Sus scrofa a partir de lotes domésticos de porcos trazidos da Europa e posteriormente aclimatados são frequentes nos países do Cone Sul desde a época colonial. No entanto, a introdução de javalis "puros" em finais do século XIX e início do XX, para fins de caça, é considerado o marco inicial do processo de invasão atualmente em curso no Pampa. Na Argentina, os primeiros indivíduos foram introduzidos na província de La Pampa. No Uruguai, no departamento de Colônia pelo aristocrata Aarón de Anchorena. Conforme Debert e Scherer (2007), a migração espontânea dos animais, assomada ao contrabando com caminhões, fez com que os animais ingressassem em território brasileiro, a partir da década de 1980. 
rede de manejo estruturada em torno da Área de Proteção Ambiental (APA) do Ibirapuitã, notadamente a "Equipe Javali no Pampa", ${ }^{11}$ tem exercido em nível regional e nacional. Essa rede envolve a cooperação entre o Instituto Chico Mendes de Conservação da Biodiversidade (ICMBio), gestor da área, a Empresa Brasileira de Pesquisa Agropecuária (Embrapa), proprietários rurais e atiradores locais credenciados. Em terceiro lugar, a região se destaca por sua territorialização fronteiriça, em que regimes jurídicos e políticas de biossegurança bastante distintos entram em contato. Por fim, mas não menos importante, a proeminência das queixas de ataque à produção animal configura um cenário bastante contrastante com o panorama da invasão suína no resto do país e mesmo em outras regiões do Rio Grande do Sul, onde a destruição de lavouras é o principal problema associado à presença dos javalis.

No entanto, em que pese a territorialização fronteiriça do sítio de pesquisa e a presença de forte mobilização social contra o "inimigo", chamou-me a atenção, desde o início da etnografia, a total ausência de metáforas xenófobas ou nacionalistas para se referir aos animais. Os suínos ferais não pareciam ser odiados por sua origem nacional - isto é, como se o território brasileiro estivesse sendo tomado por animais castelhanos ${ }^{12}-$, mas sim pela similaridade do seu comportamento com o dos ladrões de gado ou abigeatários, figuras emblemáticas do Pampa gaúcho e detestados com igual força moral e simbólica em ambos os lados da fronteira. Assim, em contraste com grande parte da literatura em humanidades sobre espécies exóticas invasoras, especialmente aquela produzida no mundo anglo-saxão (Coates, 2011; Comaroff; Comaroff, 2001; Lidström et al., 2015; Potts, 2009; Sagoff, 2011), a prevalência de um conjunto de metáforas militares e defensivas parecia estar descolada de qualquer componente nacional ou étnico. Por outro lado, a questão laboral e de classe indicava ser mais relevante na produção de analogias. Como já discuti em outro lugar (Sordi; Lewgoy, 2017), vigorava entre meus interlocutores a percepção de uma continuidade entre lidas pastoris lícitas e ilícitas no contexto fronteiriço, sobretudo entre aqueles pertencentes ao estrato patronal da pecuária local.

11 Ver nota de rodapé 4.

12 No Rio Grande do Sul, castelhano é um termo utilizado de forma por vezes pejorativa para se referir aos habitantes dos países platinos. Seu uso remete às guerras de fronteira e insurreições armadas vivenciadas na região ao longo dos séculos XVIII-XIX. 
Em outras palavras, o respeito à propriedade e à honra parecia mais importante nas reações belicosas contra o javali do que quaisquer querelas sobre sua origem. Até porque, muitos interlocutores atribuíam a si próprios uma identidade binacional ou, em termos locais, doble-chapa..$^{13}$ Proprietários rurais brasileiros e uruguaios, não raro ligados por profundos vínculos de parentesco e amizade, sentiam-se unidos em uma mesma "guerra" contra os javalis, na qual a questão da vingança e da desforra moral era mais importante que qualquer conotação nacionalista ou patriótica dessa "guerra". Tal como no caso dos cães pastores que se rebelam, atacam o rebanho e são punidos exemplarmente pelo dono com seu abandono ou sacrifício (Barreto, 2015), a "guerra ao javali" de meus interlocutores parecia se dar muito mais em um registro de razia, de feuding, do que de guerra "propriamente moderna", para empregar aqui as distinções de teor evolucionista estabelecidas pela antropologia da guerra anglo-saxônica (Leirner, 2005).

Não coincidentemente, a ideia de uma dinâmica de guerra "pré-moderna", puramente predativa, em que as distinções entre caça, pastoreio e abigeato se apagam num mesmo continuum de engajamentos humano-animais de natureza agonística, permeia toda a literatura sobre a formação sociocultural da região platina. Da mesma forma, o modelo clausewitziano de guerra, centrado no Estado e na defesa territorial, não me parecia ser o mais adequado para dar conta de outro aspecto central da "guerra ao javali". Com efeito, o suíno não é apenas perseguido, capturado e abatido pelos seus inimigos humanos - é consumido por eles. Repare-se, nesse sentido, no seguinte trecho do texto de apresentação da Agaja em sua página na internet: "O javali é o único entre os predadores nocivos e exóticos a compensar parcialmente suas perdas na agricultura e criação com o consumo de sua saborosa carne, quando este lhes retorna [a agricultores e criadores] o que surrupiou. Quitam-se."

Em Livramento e região, as posições a respeito do consumo dos javalis abatidos se dividiam. Para alguns, tratava-se de um alimento perigoso, de origem incerta, que só poderia ser consumido após diversos procedimentos técnico-culinários destinados à purificação de seus riscos. Para outros, por outro lado, tratava-se de uma carne imensamente desejada, saborosa e fortificante,

13 Expressão oriunda do duplo emplacamento de automóveis, antes comum na zona fronteiriça. 
justamente por advir de um bicho de vida livre (alçado) e, portanto, mais "natural". Era bastante comum, nesse sentido, que o pessoal das estâncias ${ }^{14}$ consumisse com certa regularidade a carne dos javalis abatidos, mas dando a preferência a fêmeas e leitões capturados e engordados em gaiolas e jaulas-currais. A carne dos grandes machos solitários (cachaços) abatidos após expedições de busca ativa, por outro lado, era frequentemente consumida apenas pelos caçadores ou simplesmente descartada, por ser considerada muito forte, muito dura, muito escura e de digestão pesada.

Prevalecia, além disso, a ideia de que os cachaços carregavam mais riscos sanitários que o resto da espécie. Embora fosse comum ouvir que os machos solitários eram rançosos, compreendo que essas concepções evocam a categoria de reima no pensamento popular brasileiro, tal como definida por Klaas Woortmann (2008, p. 23):

\begin{abstract}
Além de "quentes" ou "frios", os alimentos podem ser "reimosos" ou "mansos". A "reima" - possivelmente um termo derivado de rheuma e que também designa "mau-gênio" - é uma "qualidade" do alimento que o torna ofensivo para certos estados do organismo e em certos momentos da vida da pessoa. [...] Tal como ocorre com as qualidades de "quente" e "frio", a "reima" também exprime uma relação entre o alimento e o organismo.
\end{abstract}

Dessa maneira, são considerados reimosos os bichos já maduros sexualmente, assim como os machos não castrados em contraste com os castrados (o touro em oposição ao boi, por exemplo). ${ }^{15}$ Em seguida, Woortmann (2008, p. 24) ressalta a oposição selvagem/domesticado como diacrítico da reima, de modo que "um animal será tanto mais reimoso quanto mais se opõe ao homem". Por fim, a ambiguidade é outro critério para se definir o caráter reimoso de um alimento, o

14 Atualmente, são poucos os proprietários que residem no meio rural, especialmente aqueles do grupo patronal, isto é, donos de grandes estâncias e cabanhas. Nesse sentido, entenda-se por "pessoal das fazendas" os empregados (peões, posteiros, caseiros, capatazes, etc.) que efetivamente residem nas propriedades, encarregando-se das lidas cotidianas. Entre estes, também devem ser incluídos os proprietários médios e pequenos, de corte familiar, em grande parte ainda residentes no campo.

15 Stoeckli (2015) assinala essa dimensão na diferenciação nativa entre a carne de bovinos e bubalinos. 
que se aplica aos animais que "não se enquadram nos critérios selecionados por determinada cultura para elaborar suas taxonomias" (Woortmann, 2008, p. 24). ${ }^{16}$

Ora, o cachaço cumpre todas essas expectativas de reimosidade. Via de regra, entende-se que os machos solitários ou são porcos velhos ${ }^{17}$ expulsos de uma vara por indivíduos mais novos, ou são indivíduos jovens à espera desse momento. Em ambos os casos, portadores de traços que os qualificam como reimosos (idade e impetuosidade). Desnecessário recordar a esta altura, ademais, o quanto os javalis, e especialmente os cachaços, perturbam as fronteiras entre o mundo doméstico e o mundo selvagem. Nos encontros furtivos ou humanamente conduzidos entre suínos ferais e porcas domésticas, atribui-se aos primeiros a iniciativa sexual, e não ao contrário.

Em minha dissertação de mestrado (Sordi, 2016), argumentei que embora todas as partes comíveis dos animais sejam genericamente chamadas de "carne" no léxico culinário brasileiro, algumas carnes são consideradas mais próximas do ideal carnívoro que outras, notadamente as vermelhas e, dentre estas, a bovina. É frequente, nesse sentido, encontrarmos oposições como "carne ou frango", e a sugestiva expressão "frutos do mar" para se referir aos mariscos e ao pescado. Nesse contexto, tudo se passa como se as carnes se dispusessem num espectro de maior e menor carnicidade, estando o porco numa espécie de patamar intermediário entre os ruminantes e as aves.

Em seu clássico estudo sobre o churrasco gaúcho, Maria Eunice Maciel (1996) evoca o modelo do triângulo culinário de Lévi-Strauss (2013) para assinalar a diferença entre alimentos masculinos e femininos, cotidianos e excepcionais, a partir do modo com que são preparados e das circunstâncias sociais com que são servidos, apontando para uma exoculinária conspícua e masculina dos alimentos assados em oposição a uma endoculinária comedida e feminina dos alimentos cozidos. O churrasco, com efeito, é território eminentemente masculino no Rio Grande do Sul, cabendo aos homens, na expressiva maioria dos casos, oficiar a liturgia da preparação. Nas propriedades rurais da Campanha, a marcação das reses culmina com um assado em que os homens consomem

16 Sobre a categoria reima e sua associação com o selvagem ou não doméstico, ver também Peirano (1975).

17 Era comum ouvir que os porcos eram velhacos, diabos velhos, espertos por serem velhos, entre outras expressões do tipo. 
o bago (testículos) do animal castrado. Para os campeiros mais jovens, esse ato serve como ritual de iniciação na masculinidade adulta.

O consumo do javali, animal bravio cuja carne é obtida a partir de relações de captura violenta, insere-se nessa mesma exoculinária masculina. Entende-se que consumir a sua carne é um ato extracotidiano que envolve múltiplos riscos, corroborados tanto pelas lógicas locais de comestibilidade quanto pelos saberes veterinários. Ambos os códigos recomendam que se consuma o javali muito bem assado, e que se o faça por conta e risco dos comensais. Segundo a lógica das qualidades proposta por Lévi-Strauss (2013), o ato de assar os alimentos é compreendido por muitos povos como um compromisso entre o cru e o queimado, ao passo que o cozimento se associa em muitas culturas à dimensão do podre. Aplicando aqui essa interpretação, poderíamos argumentar que a recomendação de se bem assar o javali instaura sua comestibilidade a partir da evitação dos riscos envolvidos no consumo da sua carne crua ou mal preparada, de um lado, e do extremo representado pela inutilização sanitária das carcaças, de outro, muitas vezes operada a partir de sua incineração. ${ }^{18}$

Como interpretar, antropologicamente, uma guerra que se desdobra nesses termos, isto é, em que o espólio do vencedor é a carne do inimigo em si? É em relação a esse ponto, acredito, que a percepção da etnologia ameríndia sobre a guerra pode iluminar outros aspectos presentes na "guerra ao javali". Se, no paradigma clausewitziano, a grande questão é gerenciar os tênues limites entre política e guerra, no caso amazônico, trata-se de administrar a cinzenta zona entre alimentação cotidiana e canibalismo cerimonial. Como bem nota Fausto $(2001,2002)$ em seus trabalhos sobre os Parakanã, em um contexto no qual animais também são pessoas, todo consumo carnívoro torna-se uma modalidade potencial de canibalismo, de maneira que inúmeros procedimentos rituais são empregados para distinguir o que é caça do que é guerra. No mundo indígena nas terras baixas sul-americanas, portanto, vigora uma concepção cosmogônica e sociogênica da guerra, segundo a qual o consumo (literal ou metafórico) do inimigo visa a incorporação da sua potência para a produção e reprodução

18 Esse não é, contudo, o procedimento pregado pelas autoridades ambientais e sanitárias, que recomendam sua inutilização com creolina ou seu enterramento. No limite, que se deixe suas carcaças apodrecendo a campo, já que os patógenos presentes nas carcaças muito possivelmente são os mesmos já circulantes na vida silvestre local. 
do próprio grupo. Em Tristes trópicos, Lévi-Strauss (1996, p. 366-367) sugere um contraste entre formas ocidentais e ameríndias de relação com a alteridade perigosa:

Penso em nossos costumes judiciários e penitenciários. Ao estudá-los de fora, seríamos tentados a opor dois tipos de sociedade: aquelas que praticam a antropofagia, isto é, que veem na absorção de certos indivíduos detentores de forças temíveis o único meio de neutralizá-las e mesmo de aproveitá-las; e aquelas que, como a nossa, adotam aquilo que poderíamos chamar de antropoemia (do grego emein, vomitar): postas diante do mesmo problema, elas escolhem a solução inversa, que consiste em expulsar estes seres temíveis para fora do corpo social, deixando-os, temporariamente ou definitivamente, isolados, sem contato com a humanidade, em estabelecimentos destinados a este fim. Na maioria das sociedades primitivas, este costume inspiraria um horror profundo; ele nos marcaria aos seus olhos da mesma barbárie que seríamos tentados a lhes imputar, em razão de seus costumes simétricos.

Assim considerada, a guerra moderna, clausewitziana, possui um inegável caráter antropoêmico, ou seja, em sua modalidade defensiva, visa expelir o inimigo de um determinado território, concebido como mancha bem delimitada em um tabuleiro vestfaliano. Ela é, portanto, exclusional. Em contraste, a guerra ameríndia, de caráter antropófago, tem por objetivo incluir a potência do inimigo, não só para metabolizar sua força negativa, como também para aumentar a vitalidade do próprio grupo através dos dispositivos predativos da comensalidade e do parentesco. Aplicando esse paradigma indígena à "guerra ao javali", percebe-se o quanto o consumo de sua carne envolve uma dimensão de vingança e constituição de certa masculinidade venatória, sobretudo no que tange às carcaças dos cachaços. Por outro lado, a indução de cruzamentos entre porcas domésticas e machos ferais - prática proibida, porém frequentemente observada no campo gaúcho - revela o aspecto sexual dessa dinâmica inclusional, que visa a incorporação genética das virtudes selvagens atribuídas aos javalis (força, robustez, resistência, virilidade, naturalidade, etc.) aos rebanhos domésticos.

Até aqui, referi-me quase que exclusivamente aos meus interlocutores leigos, pecuaristas e campeiros, detentores de lógicas próprias a respeito de como 
metabolizar prático-simbolicamente a ameaça colocada pelos javalis. Mas o que dizer dos agentes estatais e científicos encontrados em campo? Seria a sua "guerra" ao javali inteiramente concebível à luz do paradigma exclusional clausewitziano ou, ao contrário, identificaríamos, também entre eles, traços de uma guerra inclusional, como no caso dos proprietários rurais, campeiros e caçadores tematizados até o momento? A princípio, tudo levaria a crer que não, uma vez que as modalidades de consumo e incorporação dos suínos ferais levadas a cabo pelos atores leigos são encaradas com muito ceticismo e desconfiança por parte de veterinários, agentes sanitários e ambientais.

Com efeito, os gestores da APA do Ibirapuitã chegaram a desenvolver uma campanha de conscientização, denominada "Javali: não faça parte deste problema", tendo por objetivo demover os habitantes da unidade de conservação da ideia de cruzar javalis com suas porcas, identificando na hibridização entre lotes ferais e domésticos um dos principais eixos de propagação do problema na região. O mesmo vale para a questão do consumo alimentício das carcaças, as quais recomendam que sejam inutilizadas via incineração ou aspersão de água sanitária. No entanto, uma fala bastante expressiva da veterinária responsável pelo projeto de vigilância sanitária conduzido pela Embrapa Suínos e Aves em parceria com a APA do Ibirapuitã sugere que a vigência de outras lógicas de relação com a alteridade perigosa pode estar em jogo na ação da ciência e do Estado.

Questionada sobre o que havia motivado o Estado brasileiro a autorizar, de forma definitiva, a captura e o abate de javalis após tanta hesitação nas duas décadas anteriores, a pesquisadora lembrou que tal decisão remetia às exigências colocadas pela Organização Internacional de Saúde Animal (OIE) tendo em vista a manutenção do status de zona livre de peste suína clássica (PSC) no país, principalmente nos estados da região Sul:

Esse projeto com relação ao javali nasceu de uma demanda direta do Ministério da Agricultura para a Embrapa, porque nós já trabalhamos junto com o ministério em muitas ações de sanidade animal. O que foi que o ministério nos pediu? Bom, um projeto de pesquisa em saúde animal que envolvesse essas populações [asselvajadas], para dar subsídio às domésticas. Quando eu comecei a rascunhar a possibilidade de trabalhar com essa população, eu comecei a me deparar com as dificuldades institucionais. Porque, ainda naquela época, do ponto de vista 
legal, no nosso país, ela [a espécie] não estava reconhecida como uma espécie exótica invasora, nociva. E por ser uma espécie de vida livre, era considerada, assim, no limbo. Ela estava quase considerada como qualquer outro animal da fauna nativa, silvestre. Em outras palavras, era crime ambiental colocar a mão no javali. Então, a primeira coisa que eu fiz foi: o que tem de informação sobre esse bicho? Aí, vai no Ibama, vai no ICMBio, e todos reconheciam, mas ninguém estava com o arcabouço legal para enfrentar o problema. E a questão ambiental tem um peso muito forte. Requer uma mobilização institucional, social, muito grande. Mas às vezes a gente não consegue só com o apelo ambiental, infelizmente. Mas quando o Ministério da Agricultura se manifestou em função dos riscos sanitários e tal, aí sim, houve uma aliança entre esses órgãos, que a gente teve o desafio - e o privilégio - de mediar via esse projeto. (Transcrição, julho de 2014).

Como se depreende dessa fala, o argumento biossecuritário foi o elemento determinante para a decretação da nocividade do javali no Brasil, haja vista a relevância da suinocultura para a produção agropecuária brasileira. ${ }^{19}$ No capítulo de seu Código de Animais Terrestres (World Organization for Animal Health, 2016) referente à PSC, a OIE trabalha com uma definição de "porco" (pig) que contempla tanto os lotes domésticos quanto os de vida livre do Sus scrofa. No entanto, a organização estabelece uma distinção entre porcos domésticos e selvagens confinados (captive wild), de um lado, e porcos selvagens e ferais, de outro, exigindo que todos sejam monitorados para fins de reconhecimento sanitário de seus países-membros ou de regiões específicas desses países, como é o caso do Brasil.

Entre os critérios estabelecidos pela organização para a obtenção do zoneamento livre para PSC, destacam-se a existência de um programa local de vigilância das populações de vida livre (wild and feral pigs), capaz de identificar sua distribuição territorial e garantir que essas populações se encontram fisicamente separadas dos suínos confinados, sejam eles domésticos ou selvagens (World Organization for Animal Health, 2016). Até aqui, tudo parece se orientar

19 Com 3,97 milhões de toneladas produzidas em 2018, o Brasil é o quarto maior produtor de carne suína do mundo, perdendo apenas para a China, a União Europeia e os Estados Unidos. É também o quarto maior exportador e o quinto maior consumidor, com uma taxa anual de 15,9 kg per capita. Os três estados da região Sul do país lideram o ranking nacional de produção e exportação (cf. Embrapa Suínos e Aves, 2019). 
por uma clássica lógica de guerra exclusional, clausewitziana e vestfaliana, e que, como bem nota Hinchliffe (2013, p. 204), espelha a tendência biossecuritária contemporânea de se considerar a relação entre vida livre e vida confinada como intrinsecamente problemática, o que tem feito com que a ecologia dos criatórios se torne "cada vez mais distinta, simbólica e materialmente, do ambiente ao seu entorno". ${ }^{20}$

Por outro lado, garantir que suínos confinados e de vida livre não estejam em contato é apenas parte das exigências colocadas pela OIE aos Estados-membros. Em seu programa de vigilância para PSC, estes devem indicar à organização que possuem informações sobre a ecologia e a condição sanitária dos lotes selvagens e asselvajados, o que implica o acesso científico-experimental às suas carcaças. Nas eloquentes e reveladoras palavras da veterinária da Embrapa, frente às exigências da OIE, foi preciso que o Estado brasileiro encontrasse meios de "botar a mão no bicho". Também foi nesse contexto, relata a profissional, que a parceria com os órgãos ambientais que regulam a caça no Brasil, Ibama e ICMBio, tornou-se imperativa para o Ministério da Agricultura, assim como a aproximação entre Estado e caçadores antes ilegais, convertidos pela instrução normativa 03/2013 em "controladores" ou "manejadores" (Instituto Brasileiro do Meio Ambiente e dos Recursos Naturais Renováveis, 2013). Mais do que isso, a veterinária classificou os indivíduos engajados no manejo como os "olhos e ouvidos do sistema veterinário oficial", o que se assemelha ao papel análogo exercido pelos birdwatchers etnografados por Keck (2015b) em Taiwan e Hong Kong.

Ao contrário dos observadores de pássaros, no entanto, manejadores de javalis matam estes últimos, em um contexto de interações que meus interlocutores não hesitam em caracterizar como de guerra. Não menos importante, parte do espólio dessa guerra é cobrado pelo Estado e seu aparato técnico-científico, ao menos nas propriedades envolvidas no projeto com a Embrapa. Durante a etnografia, acompanhei algumas saídas de campo dos pesquisadores do projeto para coletas de amostra de sangue e tecido em algumas estâncias e fazendas, bem

20 Para o autor, isso gera uma configuração paradoxal, na medida em que quanto mais os animais da pecuária intensiva se isolam do seu entorno, mais e mais se tornam vulneráveis no caso de um contato acidental. Neste sentido, o atual sistema agroalimentar seria uma verdadeira "casa de máquinas" (Hinchliffe, 2013, p. 201) para crises como as do vírus H1N1 e a iminente falência da eficácia dos antibióticos atuais. 
como para a realização de necropsias em alguns animais abatidos. Em uma dessas atividades, realizada em maio de 2016 na Estância Renascença, interior do município de Livramento, foram realizados exames em quatro leitões, presos em uma gaiola de madeira e abatidos na hora, e em dois indivíduos adultos, um macho e uma fêmea, capturados ao longo das noites anteriores.

Como em outras oportunidades, a liturgia das necropsias se compunha das seguintes etapas: primeiramente, extraíam-se as tonsilas e os linfonodos cervicais dos javalis. Logo em seguida, seccionavam-se partes de órgãos viscerais como fígado, baço, intestino delgado, pulmões e rins. Do estômago, perfurado com uma faca, extraía-se o bolo alimentar com a mão. Uma vez coletado, o conteúdo gástrico era depositado em pequenos potes de plástico, similares a embalagens de mel. Nestes, uma solução de formol e ácido acético fazia o trabalho de conservação. A abertura do estômago era considerada a parte mais desagradável de toda a necropsia, dado o forte odor exalado pela exposição do seu conteúdo ao ar. Por outro lado, era a mais imediatamente reveladora, já que, ao contrário das análises laboratoriais, um rápido exame a olho nu já conseguia identificar, de forma genérica, do que se compunha a dieta dos animais. Em seguida, as pesquisadoras extraíam os linfonodos mediastinos e mesentéricos, localizados entre os órgãos viscerais. Terminado um animal, passava-se para outro, e assim sucessivamente.

Depois de extraídas, as amostras eram colocadas em envelopes plásticos de tamanhos diferentes. Na lateral de cada um, escrevia-se o tipo de tecido coletado e o número designado para cada suíno, de um a sete. Lacrados, os envelopes eram depositados num saco maior, também transparente, que reunia todas as amostras de um mesmo bicho. Ao final do exame, acondicionava-se tudo em uma caixa refrigerada. De Livramento, essas partes do javali, consideradas as mais relevantes para a pesquisa ecológica e epidemiológica, seguiriam para Porto Alegre e Concórdia (SC), sede da Embrapa Suínos e Aves, onde alimentariam três projetos de pesquisa em três instituições diferentes. Associadas a instrumentos como anticoagulantes, reagentes, microscópios, centrífugas, etc., esperava-se que essas amostras revelassem algo de importante sobre o modo de vida e a condição sanitária dos javalis. Traduzidas em relatórios e artigos científicos, essas informações poderiam subsidiar novos protocolos de manejo da espécie, ampliando o conhecimento oficial a seu respeito e fornecendo aos agentes públicos novas estratégias de intervenção. 
Entendo que a exploração experimental das carcaças dos suínos reproduz, em outro nível, a mesma dinâmica de consumo produtivo - ou de "predação familiarizante", para empregar os termos de Fausto $(2001,2002)$ - que perpassa a "guerra ao javali" no plano pessoal dos proprietários rurais. Nos dois casos, tem-se como objetivo incorporar a potência do inimigo para melhor metabolizar sua ameaça: seja em um sentido moral e gastronômico, como empreendido pelos pecuaristas e caçadores locais, seja em um sentido cognitivo e biopolítico, como levado a cabo pelos veterinários e epidemiologistas do projeto de vigilância sanitária.

\section{Considerações finais}

De acordo com Goldman (2003, p. 460), “uma teoria etnográfica procede um pouco à moda do pensamento selvagem", tal como conceituado por Lévi-Strauss. Ou seja, ela emprega "elementos muito concretos coletados no trabalho de campo e por outros meios a fim de articulá-los em proposições um pouco mais abstratas, capazes de conferir inteligibilidade aos acontecimentos e ao mundo". Neste artigo, nada mais fiz do que procurar levar a sério as analogias traçadas pelos meus interlocutores em campo, e examinar que tipo de "guerra" seria essa travada entre homens e suínos nos campos do Sul.

Para isso, examinei os pressupostos que moldam o paradigma moderno do conflito bélico e sua extensão para o campo da ecologia e da biossegurança, assinalando seu imaginário eminentemente territorial (vestfaliano) e estatal (clausewitziano). Em seguida, a partir da insuficiência desse modelo para dar conta de alguns aspectos cruciais da "guerra ao javali" observada em campo, sugeri que outras formas de se conceber a guerra poderiam ser mobilizadas antropologicamente, abrindo espaço para que o pensamento indígena sobre a relação com o inimigo e a ameaça violenta nos dissesse algo sobre o conflito predativo estabelecido por meus interlocutores com os suínos ferais. Assim, se, como já defendi em outra oportunidade (Sordi; Lewgoy, 2017), o caráter dos javalis como abigeatários e bichos bandidos é mais do que uma metáfora para os criadores da região, também entendo que o seja a guerra oriunda dessa condição, travada e concebida a partir do arcabouço sociocosmológico resultante da constituição do Pampa como fronteira pastoril. 
Nesse sentido, um terceiro imaginário bélico poderia ser evocado para dar sentido à guerra ao javali na fronteira brasileiro-uruguaia: o da "guerra justa" ou "pacificadora", movida contra elementos internos considerados bárbaros, perigosos ou conflituosos, até hoje em voga, sob distintas formas, tanto na relação entre Estado e sociedade no Brasil (Souza et al., 2017) quanto na própria atuação externa das Forças Armadas brasileiras, vide o recente caso da Missão das Nações Unidas para a Estabilização do Haiti (Minustah). ${ }^{21}$ Com relação a esse ponto, é eloquente o fato de a ocupação fundiária da região de Livramento ter se iniciado com a distribuição de sesmarias aos combatentes do "Exército Pacificador" da Primeira Campanha da Cisplatina, enviado em 1811 pela Coroa Portuguesa para pacificar a Banda Oriental (atual Uruguai), a pedido do governador de Montevidéu (Farinatti, 2007). Essas reverberações históricas, entretanto, já foram tratadas em pormenor em outros trabalhos (Sordi, 2017; Sordi; Lewgoy, 2017).

Como espero ter demonstrado, o imaginário vestfaliano e clausewitziano da guerra moderna é bastante útil para se pensar alguns aspectos dessa guerra, mas não todos. $O$ recurso ao pensamento ameríndio e sua dinâmica canibal-inclusional permitiu-nos ir além do paradigma defensivo-exclusional que permeia a discussão sobre espécies exóticas invasoras e ameaças biológicas em geral, demonstrando que outras formas de se pensar o conflito bélico podem ser acionadas para compreendermos o que está em jogo quando nossos interlocutores afirmam estar "em guerra" contra coletivos não humanos. Logo, se é fato que os temas marciais da contenção e prontidão permeiam as lógicas contemporâneas de biossegurança, há motivos suficientes para se supor que outros mecanismos de imunização perante ameaça externa se fazem presentes. Mecanismos propriamente inclusionais e - por que não? - canibais de metabolização do risco, mais próximos da lógica de incorporação do inimigo vigente no pensamento ameríndio.

21 Agradeço aos pareceristas anônimos do artigo e a Rodrigo Charafeddine Bulamah por chamarem atenção a esse ponto. 


\section{Referências}

BARRETO, E. 'Por dez vacas com cria eu não troco meu cachorro': as relações entre humanos e cães nas atividades pastoris do Pampa brasileiro. 2015. Dissertação (Mestrado em Antropologia) - Instituto de Ciências Humanas, Universidade Federal de Pelotas, Pelotas, 2015.

BARRIOS-GARCÍA, M. N.; BALLARI, S. Impact of wild boar (Sus scrofa) in its introduced and native range: a review. Biological Invasions, n. 14, p. 2283-2300, 2012.

BRASIL. Ministério do Meio Ambiente. Secretaria de Biodiversidade e Florestas. A convenção sobre diversidade biológica (CDB). Brasília, 2000.

BRASIL. Ministério do Meio Ambiente. Secretaria de Biodiversidade e Florestas. Espécies exóticas invasoras: situação brasileira. Brasília, 2006.

BRASIL. Ministério da Defesa. Comando do Exército. Comando Logístico. Diretoria de Fiscalização de Produtos Controlados. Instrução técnico-administrativa n. 01 de 30 de abril de 2014. Regula procedimentos relativos à expedição de Guia de Tráfego. Brasília, 2014.

BRAUN, B. Power over life: biosecurity as biopolitics. In: DOBSON, K.; TAYLOR, S. L.; DOBSON, A. (ed.). Biosecurity: the socio-politics of invasive species and infectious diseases. London: Routledge, 2013. p. 45-58.

CLASTRES, P. Arqueologia da violência: ensaio de antropologia política. São Paulo: Cosac Naify, 2004.

CLEMENTS, F. Nature and structure of the climax. The Journal of Ecology, v. 24, n. 1, p. 252-284, 1936.

COATES, P. Over here: American animals in Britain. In: ROTHERHAM, I. D.; LAMBERT, R. A. (ed.). Invasive and introduced plants \& animals: human perceptions, attitudes and approaches to management. London: Earthscan, 2011. p. 39-54.

COLAUTTI, R.; MacISAAC, H. A neutral terminology to define invasive species. Diversity and Distributions, n. 10, p. 135-141, 2004.

COLLIER, S.; LAKOFF, A.; RABINOW, P. Biosecurity: towards an anthropology of the contemporary. Anthropology Today, v. 20, n. 5, p. 3-7, 2004.

COMAROFF, J.; COMAROFF, J. L. Naturing the nation: aliens, apocalypse and the postcolonial state. Journal of Southern African Studies, v. 27, n. 3, p. 627-651, 2001.

CROSBY, A. W. Imperialismo ecológico: a expansão biológica da Europa 900-1900. São Paulo: Companhia das Letras, 2011. 
DEBERT, A. J.; SCHERER, S. O javali asselvajado: ocorrência e manejo da espécie no Brasil. Natureza e Conservação, v. 5, n. 2, p. 31-44, 2007.

DIKÖTTER, F. Mao's great famine: the history of China's most devastating catastrophe. London: Bloomsbury, 2011.

EMBRAPA SUÍNOS E AVES. Estatísticas | Desempenho da produção. 15 maio 2019. Disponível em: https://www.embrapa.br/suinos-e-aves/cias/estatisticas. Acesso em: 20 jun. 2019.

FARINATTI, L. A. Confins meridionais: famílias de elite e sociedade agrária na Fronteira Sul do Brasil (1825-1865). 2007. Tese (Doutorado em História) - Instituto de Filosofia e Ciências Sociais, Universidade Federal do Rio de Janeiro, Rio de Janeiro, 2007.

FAUSTO, C. Inimigos fiéis: história, guerra e xamanismo na Amazônia. São Paulo: Edusp, 2001.

FAUSTO, C. Banquete de gente: comensalidade e canibalismo na Amazônia. Mana, v. 8, n. 2, p. 7-44, 2002.

FORTANÉ, N.; KECK, F. How biosecurity reframes animal surveillance. Revue d'anthropologie des connaissances, v. 9, n. 2, p. a-1, 2015.

GOLDMAN, M. Os tambores dos mortos e os tambores dos vivos. Etnografia, antropologia e política em Ilhéus, Bahia. Revista de Antropologia, São Paulo, v. 46, n. 2, p. 455-476, 2003.

HELMREICH, S. How scientists think; about 'natives', for example: a problem of taxonomy among biologists of alien species in Hawaii. Journal of the Royal Anthropological Institute, v. 11, n. 1, p. 107-128, 2005.

HINCHLIFFE, S. The insecurity of biosecurity: remaking emerging infectious diseases. In: DOBSON, K.; TAYLOR, S. L.; DOBSON, A. (ed.). Biosecurity: the socio-politics of invasive species and infectious diseases. London: Routledge, 2013. p. 199-214.

INGOLD, T. Globes and spheres: the topology of environmentalism. In: INGOLD, T. The perception of the environment: essays in livelihood, dwelling and skill. London: Routledge, 2000. p. 209-218.

INGOLD, T. The life of lines. London: Routledge, 2015.

INSTITUTO BRASILEIRO DO MEIO AMBIENTE E DOS RECURSOS NATURAIS RENOVÁVEIS. Instrução normativa n. 03/2013, de 31 de janeiro de 2013. Decreta a nocividade do javali e dispõe sobre o seu manejo e controle. Brasília, 2013. 
INSTITUTO BRASILEIRO DO MEIO AMBIENTE E DOS RECURSOS NATURAIS RENOVÁVEIS. Instrução normativa n. 12/2019, de 04 de janeiro de abril de 2019. Institui o sistema de controle e manejo de javalis (Sus scrofa). Brasília, 2019.

KECK, F. As relações homens/animais em Lévi-Strauss. R@U: Revista de Antropologia da UFSCar, v. 7, n. 1, p. 97-107, 2015a.

KECK, F. Sentinels for the environment. Birdwatchers in Taiwan and Hong Kong. China Perspectives, n. 2, p. 43-52, 2015b.

LACOSTE, Y. A geografia: isso serve, em primeiro lugar, para fazer a guerra. Campinas: Papirus, 1989.

LARSON, B. M. H. The war of the roses: demilitarizing invasion biology. Frontierns in Ecology and Environment, v. 3, n. 9, p. 495-500, 2005.

LATOUR, B. Jamais fomos modernos: ensaio de antropologia simétrica. São Paulo: Editora 34, 1994.

LEIRNER, P. Perspectivas antropológicas da guerra. BIB: Revista Brasileira de Informação Bibliográfica em Ciências Sociais, n. 60, p. 43-63, 2005.

LÉVI-STRAUSS, C. Tristes trópicos. São Paulo: Companhia das Letras, 1996.

LÉVI-STRAUSS, C. A lição de sabedoria das vacas loucas. Estudos Avançados, v. 23, n. 67, p. 211-216, 2009.

LÉVI-STRAUSS, C. As estruturas elementares do parentesco. Petrópolis: Vozes, 2011.

LÉVI-STRAUSS, C. The culinary triangle. In: COUNIHAN, C.; VAN ESTERIK, P. (ed.). Food and culture: a reader. New York: Routledge, 2013. p. 40-47.

LIDSTRÖM, S. et al. Invasive narratives and the inverse of slow violence: alien species in science and society. Environmental Humanities, n. 7, p. 1-40, 2015.

LOWE, S. et al. 100 of the world's worst invasive alien species: a selection from the Global Invasive Species Database. Auckland: ISSG, 2004.

MACIEL, M. E. Churrasco à gaúcha. Horizontes Antropológicos, Porto Alegre, ano 2, n. 4, p. 34-48, 1996.

MANCERON, V.; ROUÉ, M. Les animaux de la discorde. Ehtnologie Française, n. 39, p. 5-10, 2009.

McNEELY, J. A. Xenophobia or conservation: some human dimensions of invasive alien species. In: ROTHERHAM, I. D.; LAMBERT, R. A. (ed.). Invasive and introduced plants \& animals: human perceptions, attitudes and approaches to management. London: Earthscan, 2011. p. 19-38. 
PEARCE, F. The new wild: why invasive species will be nature's salvation. London: Icon Books, 2015.

PEIRANO, M. Proibições alimentares numa comunidade de pescadores (Icaraí, Ceará). 1975. Dissertação (Mestrado em Antropologia Social) - Universidade de Brasília, Brasília, 1975.

POTTS, A. Kiwis against possums: a critical analysis of anti-possum rhetoric in Aotearoa New Zealand. Society and Animals, n. 17, p. 1-20, 2009.

SAGOFF, M. Who is the invader? Alien species, property rights and the police power. In: ROTHERHAM, I. D.; LAMBERT, R. A. (ed.). Invasive and introduced plants \& animals: human perceptions, attitudes and approaches to management. London: Earthscan, 2011. p. 79-108.

SAHLINS, M. O “pessimismo sentimental” e a experiência etnográfica: por que a cultura não é um "objeto" em extinção. Mana, v. 3, n. 1, p. 41-73, 1997.

SEGATA, J. A doença socialista e o mosquito dos pobres. Iluminuras, v. 17, n. 42, p. 372389, 2016.

SIMBERLOFF, D. Confronting introduced species: a form of xenophobia?. Biological Invasions, n. 5, p. 179-192, 2003.

SIMBERLOFF, D. The rise of modern invasion biology and American attitudes towards introduced species. In: ROTHERHAM, I. D.; LAMBERT, R. A. (ed.). Invasive and introduced plants \& animals: human perceptions, attitudes and approaches to management. London: Earthscan, 2011. p. 121-135.

SIMBERLOFF, D. Invasive species: what everyone needs to know. Oxford: Oxford University Press, 2013.

SMOUT, C. How the concept of alien species emerged and developed in 20th-Century Britain. In: ROTHERHAM, I. D.; LAMBERT, R. A. (ed.). Invasive and introduced plants \& animals: human perceptions, attitudes and approaches to management. London: Earthscan, 2011. p. 55-66.

SORDI, C. Guerra ao javali: invasão biológica, feralização e domesticação nos campos sulinos.R@U: Revista de Antropologia da UFSCar, v. 7, n. 1, p. 59-77, 2015.

SORDI, C. De carcaças e máquinas de quatro estômagos: controvérsias sobre o consumo e a produção de carne no Brasil. Porto Alegre: Editora da UFRGS, 2016.

SORDI, C. Presenças ferais: invasão biológica, javalis asselvajados (Sus scrofa) e seus contextos no Brasil Meridional em perspectiva antropológica. 2017. Tese (Doutorado em Antropologia Social) - Instituto de Filosofia e Ciências Humanas, Universidade Federal do Rio Grande do Sul, Porto Alegre, 2017. 
SORDI, C. Espécies exóticas, invasões biológicas e o imaginário biopolítico da modernidade: aproximações desde a antropologia ambiental. In: VEIGA, I. S.; CALEGARO, C.; MADARASZ, N. R. (org.). Sociedade e ambiente: direito e estado de exceção. Caxias do Sul: Educs, 2018. p. 66-81.

SORDI, C.; LEWGOY, B. Javalis no pampa: invasões biológicas, abigeato e transformações da paisagem na fronteira brasileiro-uruguaia. Horizontes Antropológicos, Porto Alegre, ano 23, n. 48, p. 75-98, 2017.

SOUZA, A. B. de et al. (org.). Pacificar o Brasil: das guerras justas às UPPs. São Paulo: Alameda, 2017.

STOECKLI, P. Laços brutos: vaqueiros e búfalos no Baixo Araguari - Amapá. 2015. Tese (Doutorado em Antropologia Social) - Universidade de Brasília, Brasília, 2015.

VIVEIROS DE CASTRO, E. A inconstância da alma selvagem: e outros ensaios. São Paulo: Cosac Naify, 2011.

VIVEIROS DE CASTRO, E. Metafísicas canibais: elementos para uma antropologia pós-estrutural. São Paulo: Cosac Naify: n-1 edições, 2015.

WARREN, C. Natives and nationhood: what species 'belong' to post-devolution Scotland?. In: ROTHERHAM, I. D.; LAMBERT, R. A. (ed.). Invasive and introduced plants \& animals: human perceptions, attitudes and approaches to management. London: Earthscan, 2011. p. 67-79.

WOORTMANN, K. Quente, frio e reimoso: alimentos, corpo humano e pessoas. Caderno Espaço Feminino, v. 19, n. 1, p. 17-30, 2008.

WORLD ORGANIZATION FOR ANIMAL HEALTH. Terrestrial animal health code. Paris, 2016.

Recebido:27/06/2019 Aceito: 14/11/2019 | Received:6/27/2019 Accepted:11/14/2019 